\title{
Classificação das alterações pulmonares na leishmaniose visceral canina
}

\section{Classification of pulmonary alterations in canine visceral leishmaniasis}

\author{
Nilton Andrade Magalhães, ${ }^{* *}$ Flaviane Alves de Pinho, ${ }^{* *}$ Fernando Luis Oliveira, ${ }^{* *}$ Kleverton Ribeiro da Silva, ${ }^{* *}$ \\ Francisco Assis Lima Costa, ${ }^{* * *}($ in memoriam)
}

\begin{abstract}
Resumo
O objetivo deste estudo foi identificar e classificar as alterações pulmonares de cães naturalmente infectados por Leishmania (Leishmania) infantum conforme as manifestações clínicas. Após o diagnóstico para LV pelo exame parasitológico, 24 cães infectados foram subdivididos em dois grupos: 10 cães com até quatro sinais clínicos; e 14 cães com cinco ou mais sinais clínicos. Como controle foram avaliados cinco cães sadios. Amostras de tecido pulmonar foram coradas com hematoxilina-eosina (H-E) e Tricrômico de Masson para avaliação histopatológica, e prata-metenamina de Grocott para excluir infecções fúngicas, bem como imunoperoxidase para deteç̧ão de Leishmania. A análise microscópica do pulmão revelou espessamento focal do septo interalveolar devido à congestão, edema e infiltrado celular. Além disso, presença de fibrose, exsudato bronquiolar e ainda descamação do epitélio bronquiolar com perda de cílios, presença de hemossiderina e hiperplasia de células caliciformes. $O$ padrão de lesão fibrótico-celular predominou nos cães infectados com cinco ou mais sinais clínicos. Em contrapartida, fibrose estava presente em intensidade maior no grupo nos cães infectados com até quatro sinais clínicos. A análise imunoistoquímica mostrou maior intensidade de antígeno e amastigotas de Leishmania nos cães infectados com cinco ou mais sinais clínicos. A análise semi-quantitativa do antígeno mostrou correlação positiva de acordo com a intensidade da fibrose. Concluiu-se que a presença do parasita e seus antígenos modificam a arquitetura pulmonar evoluindo, em sua maioria, para o padrão fibrótico-celular em associação à intensidade das manifestações clínicas.
\end{abstract}

Palavras-chave: cão, pulmão, Leishmania, fibrose.

\begin{abstract}
The aim of this study was to identify and classify the pulmonary alterations in dogs naturally infected by Leishmania (Leishmania) infantum according to clinical manifestation. After diagnosis to VL by parasitological exam, 24 infected dogs were subdivided in two groups: 10 dogs with until four clinical signs; and 14 dogs with five or more clinical signs. As control were evaluated 5 healthy dogs. Pulmonary tissue samples were stained by hematoxylin-eosin (H-E) and Masson's Trichrome to histopathological examination, and Grocott's methenamine silver to exclude fungal infections, as well immunoperoxidase to detection of Leishmania. Histopathological examination of the lungs showed a focal thickening of the alveolar septa due to congestion, edema and cellular infiltrate. Moreover, presence of fibrosis, bronchiolar exudate and flaking of the bronchiolar epithelium, presence of hemosiderin and hyperplasia of goblet cell were observed. The pattern fibrotic-cellular lesions predominated in most infected dogs but mainly in infected dogs with five or more signs clinical. However, fibrosis was higher in infected dogs with four signs clinical. Immunoperoxidase staining showed amastigotes and/or antigen of Leishmania in all infected dogs but there was an increase significant in infected dogs with five or more signs clinical. Semi-quantitative analysis of intensities antigen reveled a positive correlation between fibrosis in infected dogs. In conclusion, the presence of the parasite and/or antigens modifies the lung architecture due for fibrotic-cellular pattern in infected dogs with severe manifestation clinical.
\end{abstract}

Keywords: dog, lung, Leishmania, fibrosis.

\section{Introdução}

Nas Américas, a leishmaniose visceral (LV) é uma zoonose causada pelo protozoário L. (L.) infantum (Mauricio et al., 2000; Alvar, 2012). O cão tem um papel importante na epidemiologia da LV por apresentar um alto parasitismo cutâneo, desse modo, tornando-se uma fonte de infecção para o inseto vetor (Soares et al., 2011).
$\mathrm{Na}$ leishmaniose visceral canina (LVC) as alterações histopatológicas em órgãos pertencentes ao sistema fagocítico já estão muito bem descritas como no fígado, baço e linfonodos (Gonzalez et al., 1988; Alexandre-Pires et al., 2006; Costa et al., 2008; Tasca et al., 2009). No entanto, outros órgãos podem ser afetados pela Leishmania como os pulmões. Há poucos relatos na literatura descrevendo as alterações clínico-patológicas e a interação parasito-hospedeiro nesse compartimento (Duarte e

${ }^{*}$ Recebido em 4 de dezembro de 2014 e aceito em 21 de março de 2016.

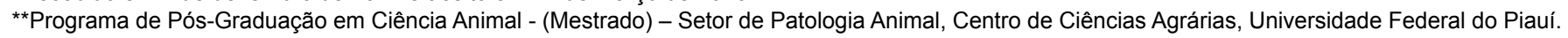

***Setor de Patologia Animal, Centro de Ciências Agrárias, Universidade Federal do Piauí. Campus Socopo, 64049-550 - Teresina, PI.

Autor para correspondência: nilton_vet@hotmail.com. 
Corbett, 1984; Duarte et al., 1986; Gonçalves et al., 2003; Alves et al., 2010).

A presença de Leishmania no tecido pulmonar é rara, mas antígenos do parasito são frequentemente encontrados, sugerindo que os parasitos passam pelos pulmões, desencadeiam alterações, mas não permanecem no órgão, apesar da presença da célula hospedeira do parasito, que é o macrófago (Tryphonas et al., 1977; Duarte e Corbett, 1984; Silva et al., 2015).

Na LVC, a pneumonite intersticial crônica é a principal alteração observada em cães doentes (Gonçalves et al., 2003). O exame microscópico revela formações granulomatosas, fibrose intersticial e raramente macrófagos parasitados (Tafuri et al., 2001). O padrão histopatológico mais observado é um espessamento do septo alveolar definido, conforme o tipo do infiltrado, em: celular, fibrótico-celular e fibrótico (Duarte et al., 1986).

Em cães com LVC da área endêmica de Teresina-PI, estudos demonstram alterações pulmonares como espessamento do septo alveolar devido à congestão, infiltrado inflamatório, proliferação de células epiteliais e fibroblastos em cães sintomáticos e assintomáticos (Alves et al., 2010). No entanto, não há uma correlação dessas alterações conforme a manifestação clínica e o tipo de infiltrado. Assim, propomos neste estudo identificar e classificar as lesões pulmonares em cães naturalmente infectados por $L$. (L.) infantum conforme a gravidade das manifestações clínicas.

\section{Material e métodos}

Cães machos e fêmeas, de idades desconhecidas, foram examinados aleatoriamente para leishmaniose em levantamento epidemiológico realizado pela Gerência de Zoonoses, com base na detecção de anticorpos anti-Leishmania, pelos métodos de ELISA (Ensaio imunoenzimático) e/ou imunofluorescência indireta (IFI) - Bio-Manguinhos. Como teste padrão para confirmação da doença realizou-se exame direto para detecção de Leishmania sp em aspirado de medula óssea esternal e/ ou linfonodo poplíteo. Vinte e nove desses animais foram selecionados para este estudo. Os cães foram divididos em dois grupos: 24 cães infectados (estes foram subdivididos em: 10 cães com até quatro sinais clínicos; e 14 cães com cinco ou mais sinais clínicos); e cinco cães sadios.

Após o exame clínico, os cães foram anestesiados com tiopental sódico $(25 \mathrm{mg} / \mathrm{kg})$ e eutanasiados com injeção intravenosa de cloreto de potássio a $10 \%$. Em seguida foi realizada necropsia completa e colhidos fragmentos de $0,5 \mathrm{~cm}$ de espessura de cada lobo pulmonar (apical, médio, diafragmático e acessório) dos dois antímeros, para exame histopatológico. Antes da fixação do tecido, foram preparados imprints dos lobos pulmonares para pesquisa de Leishmania. Após esse procedimento, os fragmentos de pulmão foram fixados em formol a $10 \%$ tamponado com fosfato a $0,01 \mathrm{M} \mathrm{pH} \mathrm{7,4}$ para análise histopatológica e imunoistoquímica.

Para a análise histopatológica, os tecidos fixados em formol tamponado foram processados por técnicas de rotina, cortados a $5 \mu \mathrm{m}$ e corados com H-E para avaliação histopatológica no intuito de identificar e classificar as possíveis lesões no tecido, Tricrômio de Masson para evidenciar tecido conjuntivo e/ ou elementos fibrosos à base de colágeno (LUNA, 1968), e prata-metenamina de Grocott para excluir infecções por fungos
(GROCOTT, 1955). Para tanto, selecionamos aleatoriamente (por sorteio) dois lobos pulmonares de cada animal.

A classificação das lesões histopatológicas pulmonares foi definida como celular, quando havia predominância no infiltrado de células inflamatórias; fibrótico, quando havia predominância de fibroblastos, e fibrótico-celular, quando havia equilíbrio na presença de células inflamatórias e fibroblastos (Duarte et al., 1986).

Parasitas e seus antígenos foram detectados pela técnica de imunoistoquímica utilizando anticorpo primário anti-Leishmania amazonensis (produzido no Laboratório de Soroepidemiologia e Imunobiologia do Instituto de Medicina Tropical da Universidade de São Paulo), na diluição de 1:800. A amplificação da reação foi feita com o sistema Envision+, peroxidase (DAKO corporation, Carpinteria, USA). A revelação foi realizada com diaminobenzidina (Sigma Chemical, USA) e a contra-coloração com hematoxilina de Harrys (Sigma Chemical, USA).

O protocolo de experimentação acima descrito seguiu os critérios estabelecidos pelo Comitê de Ética em Experimentação Animal da Universidade Federal do Piauí (Processo N 004/09). Os cães controle não infectados foram doados pela Gerência de Zoonoses de Teresina-PI e pertenciam ao grupo de animais capturados para o controle da raiva urbana.

Nas análises dos dados comparativos foi utilizado o teste estatístico não paramétrico de Mann-Whitney e KruskalWallis. O nível de significância adotado foi $p<0,05$. Para as variáveis qualitativas foi aplicado o teste do qui-quadrado. Para a classificação histopatológica das lesões pulmonares e análise imunoistoquímica selecionamos dois lobos pulmonares aleatoriamente de cada animal. Os resultados foram analisados de forma semiquantitativa, mensurando-se a distribuição e intensidade das lesões, classificando-as com base numa escala de 0 a 5 , onde $0=$ normal, $1=$ mínima ou duvidosa, $2=$ média, $3=$ moderada, 4 = moderadamente severa e $5=$ severa.

\section{Resultados}

Dos 24 animais naturalmente infectados utilizadas neste estudo as manifestações clínicas mais frequentes foram: linfonodos superficiais aumentados em 18 (75\%) animais, lesões na pele em $17(70,83 \%)$, emagrecimento em $16(66,66 \%)$ e onicogrifose em 12 (50\%). Dez animais (46,6\%) apresentaram sinais respiratórios, caracterizados por tosse, espirro, dispneia e coriza, sendo que apenas um desses animais, do grupo dos cães infectados com cinco ou mais sinais clínicos, apresentou um quadro respiratório mais severo com descarga nasal catarral, tosse e dispneia.

A análise histopatológica do pulmão revelou espessamento focal do septo interalveolar nos cães infectados de ambos os grupos devido ao infiltrado celular, congestão e/ou edema, sendo que os cães infectados com mais de cinco sinais clínicos apresentaram um espessamento focal no septo alveolar com intensidade variando de mínima a moderadamente severa com diferença significante em relação aos cães controles ( $P=0,0459$, teste de Kruskal-Wallis) (Figura 1). O infiltrado celular era composto por células mononucleares como macrófagos, fibroblastos, mas principalmente linfócitos e em alguns casos raros neutrófilos. Havia presença de fibrose, exsudato bronquiolar e ainda descamação do seu epitélio, com perda de cílios, presença de hemossiderina e hiperplasia de células caliciformes. 


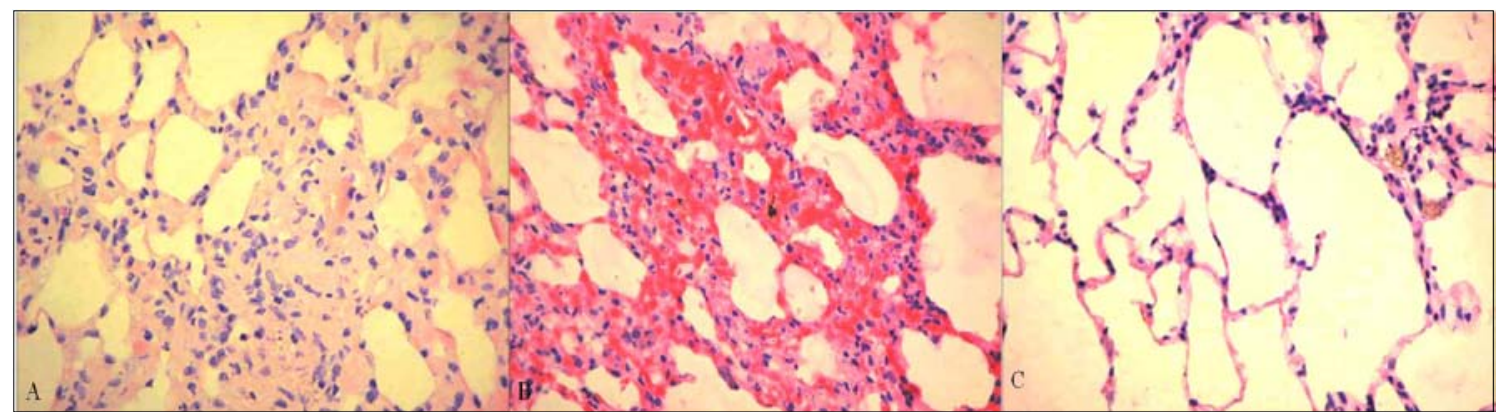

Figura 1: Pulmão de cão infectado com Leishmania infantum apresentando espessamento no septo alveolar: (A) Infiltrado celular e (B) Presença de congestão e edema. (C) Pulmão de cão não infectado com septo alveolar normal. Coloração HematoxilinaEosina. 40x.

Na classificação do tipo de infiltrado celular, avaliamos o corte histológico de 44 lobos pulmonares selecionados aleatoriamente, sendo 17 dos cães com até quatro sinais clínicos e 27 dos cães com cinco ou mais sinais clínicos. A análise histopatológica revelou que $56,81 \%$ (25/44) dos lobos pulmonares apresentavam um infiltrado celular do tipo fibróticocelular, sendo que destes $69,2 \%$ $(18 / 26)$ dos lobos pulmonares eram dos cães com cinco ou mais sinais clínicos. Em menor proporção observou-se o padrão celular e fibrótico em 15,9\% (7/44) e 25\% (11/44), respectivamente (Figura 2). A frequência do padrão fibróticocelular nos lobos pulmonares dos animais com cinco ou mais sinais clínicos foi significante quando comparado aos cães com até quatro sinais clínicos $(P=0,0232$ - teste do qui-quadrado). principalmente, nos locais de espessamento e infiltrado inflamatório sem diferença entre os cães infectados. No entanto, observamos uma diferença significante nos cães com quatro sinais clínicos em relação aos cães controle $(P=0,0463$, teste de Kruskal-Wallis) (Figura 3).
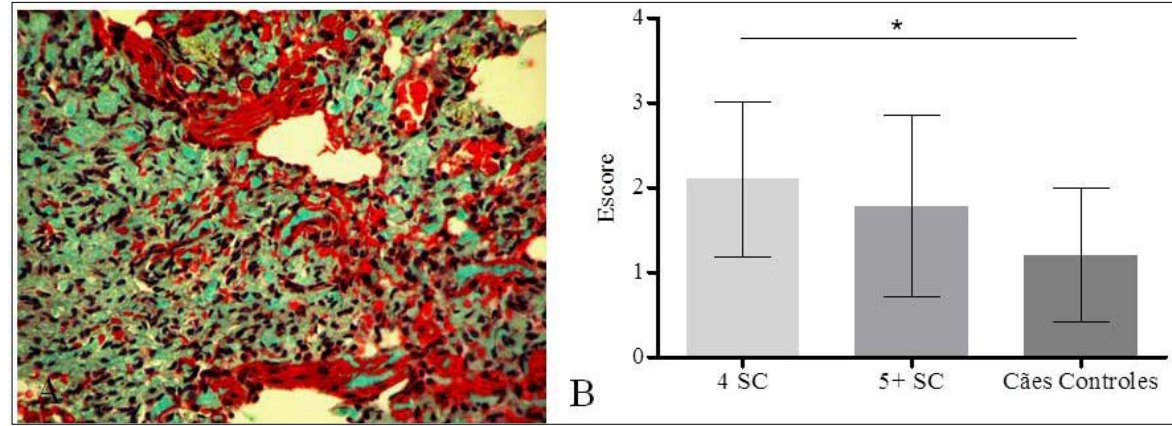

Figura 3. Pulmão de cão infectado com Leishmania infantum: (A) Presença de fibrose no septo alveolar Tricrômio de Masson. 40x. (B) Análise semi-quantitativa da presença de fibrose em lobos pulmonares de cães infectados e cães controles. 4SC= cães infectados com quatro sinais clínicos; $5+S C=$ cães infectados com cinco ou mais sinais clínicos. ${ }^{*} P<0.05$, teste de Kruskal-Wallis.

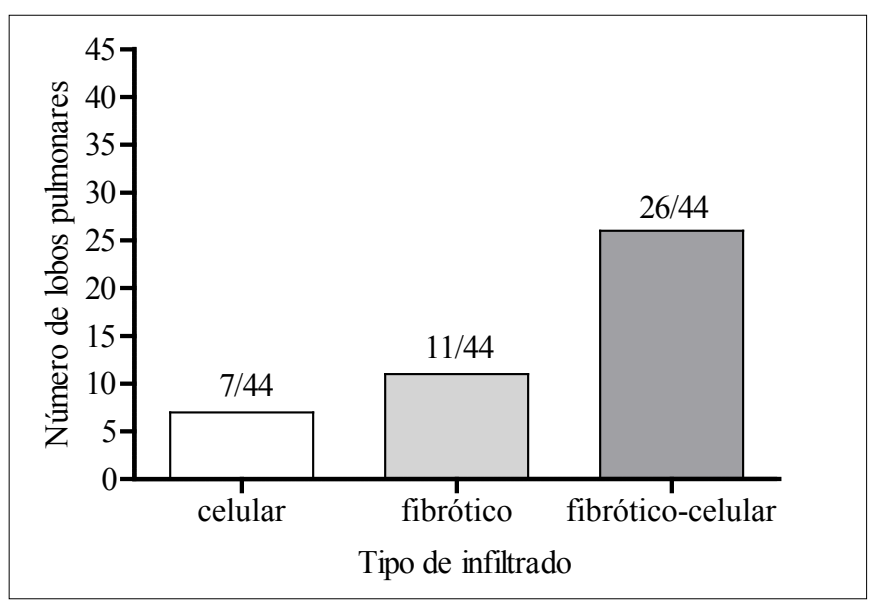

Figura 2: Tipos de infiltrado inflamatório (celular, fibrótico e fibrótico-celular) observados em 44 lobos pulmonares de cães com LV.

Pelo método de Tricrômico de Masson observamos no pulmão dos cães infectados a presença de fibrose de intensidade variando de mínima a moderada. A fibrose localizava-se,
A coloração pelo método prata-metenamina de Grocott não revelou a presença de fungos.

Os imprints de tecido pulmonar não revelaram a presença de formas amastigotas de Leishmania. Em contrapartida, na análise por imunoistoquímica pôde-se observar a presença de amastigotas e/ou antígenos de Leishmania em todos os animais infectados. A presença de amastigota de Leishmania foi observada em amostras de tecido pulmonar de quatro animais infectados em células fagocíticas do infiltrado inflamatório e/ou livres no interstício, sendo um pertencente ao grupo dos animais com quatro sinais clínicos, e três cães com cinco ou mais sinais clínicos. Em adição, antígeno estava presente em todos os 24 animais infectados, no padrão celular em células fagocíticas e como material particulado, livres no interstício. Nos animais controle, nem amastigotas nem antígeno foram encontrados. $\mathrm{Na}$ avaliação semiquantitativa da presença de antígenos no tecido pulmonar observou-se uma intensidade significantemente maior nos cães com cinco ou mais sinais clínicos em comparação aos cães com quatro sinais clínicos ( $P=0,0455$, teste Mann-Whitney) (Figura 4). 


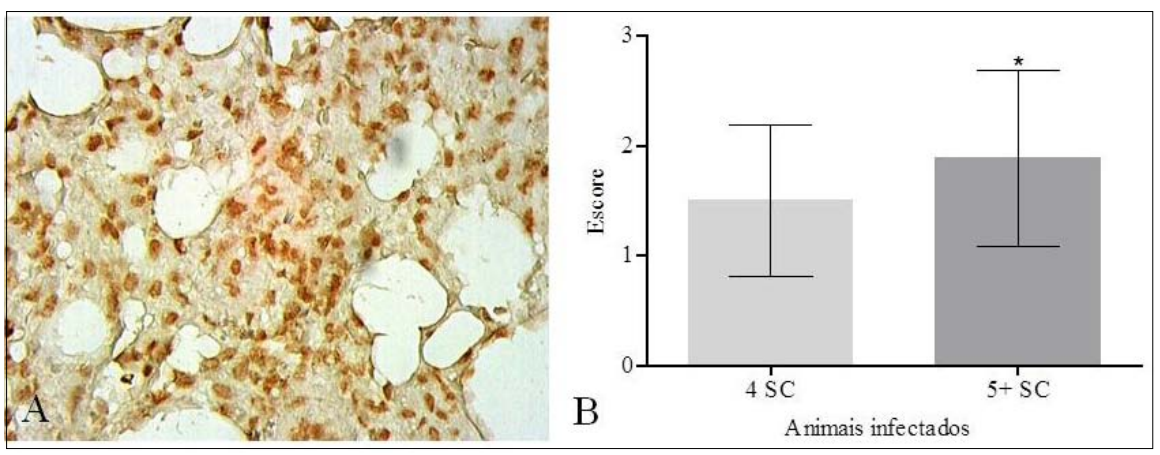

Figura 4: (A) Pulmão de cão infectado com presença de antígeno de Leishmania. Imunoperoxidase. 40x. (B) Análise semiquantitativa da presença de antígeno de Leishmania em lobos pulmonares de cães infectados e cães controle. $4 \mathrm{SC}=$ cães infectados com quatro sinais clínicos; $5+\mathrm{SC}=$ cães infectados com cinco ou mais sinais clínicos. ${ }^{*} \mathrm{P}<0.05$, teste de Mann-Whitney.

Por fim, vimos que a presença de antígenos tinha uma correlação positiva com fibrose nos cães infectados $(P=0,0392$, Teste de Pearson) (Figura 5).

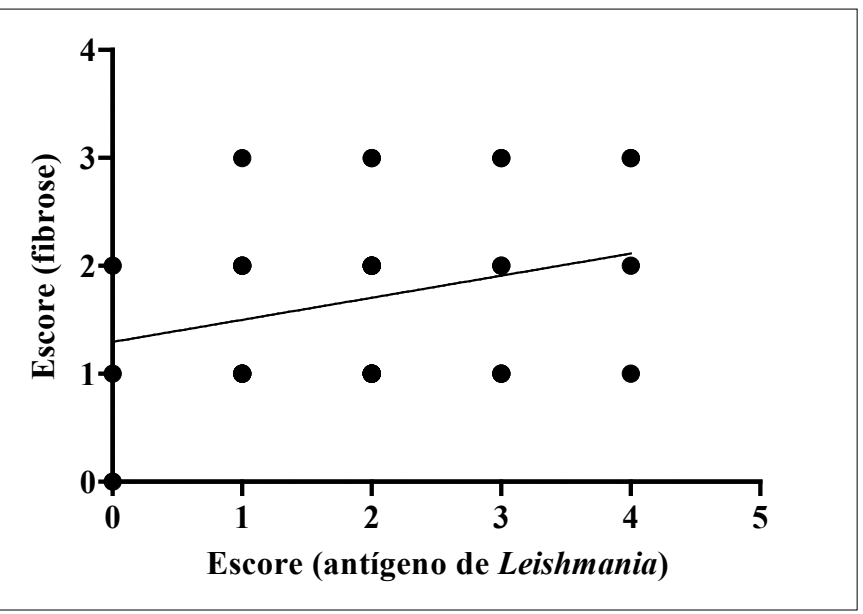

Figura 5: Correlação positiva entre presença de antígeno de Leishmania e fibrose em lobos pulmonares de cães infectados. $P=0,0392$, teste de Pearson.

\section{Discussão}

O quadro clínico da LVC é variável e depende da resposta imune do cão e da cepa do parasito inoculado pela picada do inseto vetor (Michalik e Genaro, 2005; Manna et al., 2009, Ribeiro et al., 2013; Manzillo, 2013). Mas, uma vez estabelecida a infecção, as principais manifestações clínicas são emagrecimento, linfadenopatia, lesões na pele e mucosas pálidas (Ciaramella et al., 1997; Freitas et al., 2012). Contudo, em alguns casos os cães podem apresentar sinais clínicos referentes a alterações no trato respiratório. Um dado interessante em nosso estudo é que $41,6 \%$ dos cães examinados tinham algum sinal clínico de comprometimento respiratório, diferindo da frequência vista em outros estudos que não ultrapassaram $15 \%$ dos cães acometidos pela doença (Slappendel, 1988; Denerolle, 1996; Ciaramella et al., 1997; Koutinas et al., 1999; Silva et al., 2015).

O mecanismo pelo qual a leishmaniose visceral determina as alterações pulmonares é pouco conhecido, especialmente diante da persistência da lesão e da ausência das manifes- tações clínicas no cão imunocompetente (Gonçalves et al., 2003). Isto pode ser decorrente da arquitetura pulmonar desta espécie que apresenta peculiaridades importantes de resistência às lesões, como ausência de lobulação secundária, pleura delgada, bronquíolos respiratórios bem desenvolvidos, ventilação colateral bastante eficiente e vasos com paredes delgadas, o que facilita a resolução das lesões pulmonares (Dungworth, 1994).

Dessa forma, Duarte (1986) em busca do entendimento da lesão respiratória na LVC, observou que $80,5 \%$ dos cães naturalmente infectados apresentavam pneumonia intersticial e não outra afecção respiratória, como broncopneumonia. Salientou ainda que a participação do infiltrado inflamatório é muito importante na patogênese da lesão.

Estudos posteriores têm demonstrado claramente que a pneumonite intersticial é a principal lesão pulmonar em cães com LV (Gonçalves et al., 2003; Alves et al., 2010; Silva et al., 2013). No entanto, ainda não está claro o mecanismo que envolve a persistência da lesão com uma carga parasitária tão baixa. Assim, na tentativa de buscarmos respostas sobre esse processo patológico, analisamos criteriosamente diferentes lobos pulmonares de cães infectados da área endêmica de Teresina-PI classificando as lesões conforme o tipo de infiltrado e a sua possível correlação com as manifestações clínicas e a presença do parasito.

Em concordância com os estudos já realizados em tecido pulmonar de cães com LV (Duarte et al., 1986; Gonçalves et al., 2003; Alves et al., 2010; Silva et al., 2013), a principal lesão foi pneumonite intersticial com um acentuado espessamento do septo alveolar constituído predominantemente por um infiltrado inflamatório, sobretudo nos cães com cinco ou mais sinais clínicos. Cabe salientar que a coloração de prata-metenamina de Grocott não revelou a presença de hifas que denunciasse uma infecção fúngica secundária.

Partimos também para avaliação do tipo do infiltrado inflamatório nos animais infectados na qual revelou que na maioria das lesões encontradas havia um infiltrado constituído por células mononucleares e fibroblastos $(60,46 \%)$, caracterizando o padrão de pneumonite como fibrótico-celular. Estes resultados diferem do padrão celular predominante encontrado por Duarte et al. (1986), presente em 46,49\% e por Gonçalves et al. (2003), presente em $38,88 \%$ dos animais.

Provavelmente, a pneumonite fibrótico-celular esteja relacionada com o curso crônico da infecção, muito embora não tivéssemos conhecimento do tempo de duração da mesma por se tratar de animais infectados naturalmente. A fibrose é um processo patológico que envolve a participação de diversos fatores, sendo as células inflamatórias importantes reguladoras dessa lesão. Portanto, na fibrose, independentemente da causa, é sempre visto um infiltrado de células mononucleares (Wynn, 2008).

Muito embora esteja claro o caráter fibrótico no infiltrado celular, para avaliarmos a magnitude dessa lesão, amostras de tecido pulmonar foram coradas com Tricrômio de Masson que possibilita a visualização de depósito de colágeno característico 
da fibrose (Brancoft e Gamble, 2008). Para nossa surpresa, não observamos uma diferença significante entre os grupos dos cães infectados. Vários fatores podem estar relacionados com esse achado como o período desconhecido da infecção e a virulência da cepa.

Quando avaliamos a detecção do parasito, não observamos formas amastigotas de Leishmania nos imprints. Entretanto, pela técnica de imunoistoquímica visualizamos o parasito em $16,67 \%$ dos cães infectados não diferindo da maioria dos estudos que relatam presença do parasito em média, $20 \%$ dos casos (Duarte et al., 1986; Silva et al., 2013). Mas, de acordo com Silva et al., (2013), ao lançar mão da técnica de Reação em Cadeia da Polimerase-PCR o número de casos sobe para $50 \%$. Em nosso estudo, a técnica de imunoistoquímica detectou presença de antígeno nos 24 cães infectados (100\%).

Um dado interessante é que o parasitismo foi significantemente maior nos cães infectados com cinco ou mais sinais clínicos, já que outros estudos não conseguiram demonstrar essa diferença do parasitismo conforme a gravidade das manifestações clínicas (Gonçalves et al., 2003). Em órgãos

\section{Referências}

ALEXANDRE-PIRES, G.; PAIS, D.; CORREIA, M.; PINA, J.A. Leishmaniosis - a report about the microvascular and cellular architecture of the infected spleen in Canis familiaris. Microscopy Research and Technique, v. 69, p. 227-235, 2006.

ALVAR J.; VÉLEZ, I.D.; BERN, C.; HERRERO, M.; DESJEUX, P.; CANO, J.; JANNIN, J.; DEN BOER, M. Leishmaniasis worldwide and global estimates of its incidence. PLoS ONE. v. 7, p. 1-12, 2012.

ALVES, G.B.; PINHO, F.A.; SILVA, S.M.; CRUZ, M.S.; COSTA, F.A. Cardiac and pulmonary alterations in symptomatic and asymptomatic dogs infected naturally with Leishmania (Leishmania) chagasi. Brazilian Journal of Medical and Biological Research, v. 43, n. 3, p. 310-315, 2010.

BANCROFT, J.; GAMBLE, M. Theory and practice of histological techniques, 6. ed. Churchill-Livingstone, London, England, 2008, $744 \mathrm{p}$.

CIARAMELLA, P.; OLIVA, G.; LUNA, R.D.; GRADONI, L.; AMBROSIO, R.; CORTESE, L.; SCALONE, A.; PERSECHINO, A. A retrospective clinical study of canine leishmaniasis in 150 dogs naturally infected by Leishmania infantum. Veterinary Record, v. 141, p. 539-543, 1997.

COSTA, M.M.; LIMA, W.G.; FIGUEIREDO, M.M.; MICHALICK, M.S.; TAFURI, W.L. Cervical, mandibular, and parotid lymph nodes of dogs naturally infected with Leishmania infantum: a histopathologic and immunohistochemistry study and its correlation with facial skin lesions. Veterinary Pathology, v. 45, p. 613-616, 2008.

DENEROLLE, P. Leishmaniose canine: difficultés du diagnostic et du traitement (125 cas). Pratique Médicale et Chirurgicale del Animal de Compagnie, v. 31, p. 137-145, 1996.

DUARTE, M.I.; LAURENTI, M.D.; BRANDAO NUNES, V.L.; REGO JUNIOR, A.F.; OSHIRO, E.T.; CORBETT, C.E. Interstitial pneumonitis in canine visceral leishmaniasis. Revista do Instituto de Medicina Tropical de São Paulo, v. 28, p. 431-436, 1986.

DUARTE, M.I; CORBETT, C.E. Histopathological and ultrastructural aspects of interstitial pneumonitis of experimental visceral leishmaniasis. Transaction of Royal Society of Tropical Medicine and Hygiene, v. 78, p. 683-688, 1984. classicamente atingidos pela LV como baço, fígado, linfonodos e medula óssea muitos trabalhos evidenciaram a correlação positiva entre a carga parasitária nos mesmos e os sinais clínicos (Reis et al., 2006).

Um achado que destacamos nesse estudo é a correlação positiva entre o parasitismo e a fibrose. Com base na literatura e no que observamos nesse estudo, a fibrose é uma lesão pulmonar importante (Gonçalves et al., 2003; Silva et al., 2013). Ainda não está clara a sua patogênese na LVC, mas a presença de um infiltrado inflamatório persistente desenvolvendo lesão fibrótica remonta a possibilidade de que a presença do antígeno é suficiente para manter macrófagos ativos tornando-os capazes de desencadear e manter esse processo patológico, já que a detecção do parasita é baixa no pulmão.

Com base no exposto, as lesões pulmonares encontradas em cães naturalmente infectados são frequentes e caracterizadas por pneumonite intersticial com um infiltrado inflamatório predominantemente fibrótico-celular associado à presença de formas amastigotas e/ou antígenos de Leishmania com destaque nos cães com quadro clínico mais severo.

DUNGWORTH, D.L. The respiratory system. In: Jubb, K. V. F.; Kennedy, P. C.; Palmer, N. Pathology of domestic animals. New York: Academic Press; 1994. p 539-698.

FREITAS, J.C.C.; NUNES-PINHEIRO, D.C.S.; BELARMINO EUGÊNIO LOPES NETO, B.E.L.; SANTOS, G.J.L.; CYNTIA RAFAELLE AMARAL DE ABREU, C.R.A.; BRAGA, R.R.; CAMPOS, R.M., OLIVEIRA, L.F. Clinical and laboratory alterations in dogs naturally infected by Leishmania chagasi. Revista da Sociedade Brasileira de Medicina Tropical, v. 45, n. 1, p. 24-29, 2012.

GONCALVES, R.; TAFURI, W.L.; MELO, M.N.; RASO, P. Chronic interstitial pneumonitis in dogs naturally infected with Leishmania (Leishmania) chagasi: a histopathological and morphometric study. Revista do Instituto de Medicina Tropical de São Paulo, v. 45, p. 153-158, 2003.

GONZALEZ, J.L.; ROLLAN, E.; NOVOA, C.; CASTANO, M. Structural and ultrastructural hepatic changes in experimental canine leishmaniasis. Histology and Histopathology, v. 3, p. 323329, 1988.

GROCOTT, R.G. A Stain for fungi in tissue sections and smears using Gomori Methenamine Silver Nitrate Technique. American Journal of Clinical Pathology, v. 25, p. 975, 1955.

KOUTINAS, A.F.; POLIZOPOULOU, Z.S.; SARIDOMICHELAKIS, M.N.; ARGYRIADIS, D.; FYTIANOU, A.; PLEVRAKI, K.G. Clinical considerations on canine visceral leishmaniosis in Greece: a retrospective study of 150 cases (1989-1996). Journal of the American Animal Hospital Association, v. 35, p. 376-83, 1999.

LUNA, G. L. Manual of histologic staining methods of the Armes Forces Institute of Pathology. New York McGraw Hill; p. 258, 1968.

MANNA, L.; REALE, S.; VITALE, F.; GRAVINO, A.E. Evidence for a relationship between Leishmania load and clinical manifestations. Research in Veterinary Science. v. 87, p. 76-78, 2009.

MANZILLO, V.F.; DI MUCCIO, T.; CAPPIELLO, S.; SCALONE, A.; PAPARCONE, R.; FIORENTINO, E.; GIZZARELLI, M.; GRAMICCIA, M.; GRADONI, L.; OLIVA, G. Prospective study on the incidence and progression of clinical signs in naïve dogs naturally infected by Leishmania infantum. PLoS Neglected Tropical Disease. v. 7, p. 222-225, 2013. 
MAURICIO, I.L.; STOTHARD ,J.R.; MILES, M.A. The strange case of Leishmania chagasi. Parasitology Today, v. 16, p. 188189, 2000.

MICHALICK, M.S.M; GENARO, O. Leishmaniose Visceral Americana. In: NEVES, D. P. et al. Parasitologia humana. 11. ed., São Paulo: Atheneu, 2005. p. 56-72.

REIS, A.B.; MARTINS-FILHO, O.A.; TEIXEIRA-CARVALHO, A.; CARVALHO, M.G.; MAYRINK, W.; FRANCA-SILVA, J.C.; GIUNCHETTI, R.C.; GENARO, O.; CORREA-OLIVEIRA, R. Parasite density and impaired biochemical/hematological status are associated with severe clinical aspects of canine visceral leishmaniasis. Research in Veterinary Science, v. 81, p. 68-75, 2006.

RIBEIRO, R.R.; SILVA, S.M.; FULGÊNCIO, G.O.; MICHALICK, M.S.M.; FRÉZARD, F.J.G. Relationship between clinical and pathological signs and severity of canine leishmaniasis. Revista Brasileira de Parasitologia Veterinária, v. 22, p. 373-378, 2013.

SILVA, L.C.; CASTRO, R.S.; FIGUEIREDO, M.M.; MICHALICK, M.S.M.; TAFURI, W.L.; TAFURI, W.L. Canine visceral

leishmaniasis as a systemic fibrotic disease. International Journal Experimental Pathology. v. 94, p. 133-143, 2013.

SILVA, R.C; CAFFARO K.; PAULA, C.L.; RISSETI, R.M.;

LANGONI, H.; MEGID, J.; MELANCHAUSKI, M.S.; SOUZA, K.L.; TAKAHIRA, R.K.; MACHADO, V.M.V. An atypical Toxoplasma gondii genotype in a rural Brazilian dog co-infected with Leishmania (Viannia) braziliensis. Revista da Sociedade Brasileira de Medicina Tropical, v. 48, n. 2, p. 224-227, 2015.
SLAPPENDEL, R.J. Canine leishmaniasis. A review based on 95 cases in The Netherlands. Veterinary Quarterly, v. 10, p. 1-16, 1988.

SOARES, M.R.; MENDONÇA, I.L.; BONFIM, J.M.; RODRIGUES, J.A.; WERNECK, G.L.; COSTA, C.H. Canine visceral leishmaniasis in Teresina, Brazil: Relationship between clinical features and infectivity for sand flies. Acta Tropica, v. 117, p. 6-9, 2011.

TAFURI, W.L.; DE OLIVEIRA, M.R.; MELO, M.N.; TAFURI, W.L. Canine visceral leishmaniosis: a remarkable histopathologic picture of one case reported from Brazil. Veterinary Parasitology, v. 96, p. 203-212, 2001.

TASCA, K.I.; BUZETTI, W.A.S.; TENORIO, M.S.; PAULAN, S.C.; LIMA, F.L.; QUEIROZ, N.M.G.P.; MACHADO, R.Z.; OLIVEIRA, T.M.F.; NEVES, M.F.; NORONHA Jr, A.C.F.; ASSIS, J. Exames parasitológicos, imunoistoquímicos e histopatológicos para detecção de Leishmania chagasi em tecidos esplênicos de cães com leishmaniose visceral. Revista Brasileira de Parasitologia Veterinária, v. 18, n.1, p. 27-33, 2009.

TRYPHONAS, L.; ZAWIDZKA, Z.; BERNARD, M.A.; JANZEN, E.A. Visceral leishmaniasis in a dog: clinical, hematological and pathological observations. Canadian Journal of Comparative Medicine, v. 41, p. 1-12, 1977.

WYNN T.A. Cellular and molecular mechanisms of fibrosis. Journal of Pathology. v. 214, p. 199-210, 2008. 